\section{Homeward bound}

$\mathrm{W}$

e board the Hercules for the long journey home and taxi down the runway. As I reflect on a month that seems as if it has only just begun, countless memories and images begin flooding my consciousness.

Was it only 2 weeks ago that the routine of our day had been interrupted by word that 9 Canadian casualties were being brought to our hospital?

Their armoured vehicle had driven over an improvised explosive device. Nurses, technicians, medics, physicians' assistants and doctors moved quickly to prepare our trauma bays to receive the wounded. A second surgical team was called in.

Then we waited.

We heard the helicopters approaching and our patients began coming through our doors shortly thereafter.

We all knew our roles and we all performed precisely the tasks that needed to be done. We would be very busy that day. No one shouted. Our teams asked direct questions, made requests for assistance and supplies, and offered words of comfort for the wounded as we worked quickly to assess and resuscitate.

We brought the first patient into the operating room and transferred him from his stretcher to the operating room table as gently as we could. We tried to converse with him as we untangled his monitor cables and intravenous lines.

The words come back to me: "Where are you from? ... Are you having much pain? ... Try to lie still."

One of our nurses applied an oxygen mask as I prepared to give the medications to induce anesthesia. The patient had a troubled look on his face and asked: "Wait, how are the other guys? Are they all OK?"

Blinking away tears, I exchanged glances with the nurse. Thankfully, all of the occupants of the vehicle had

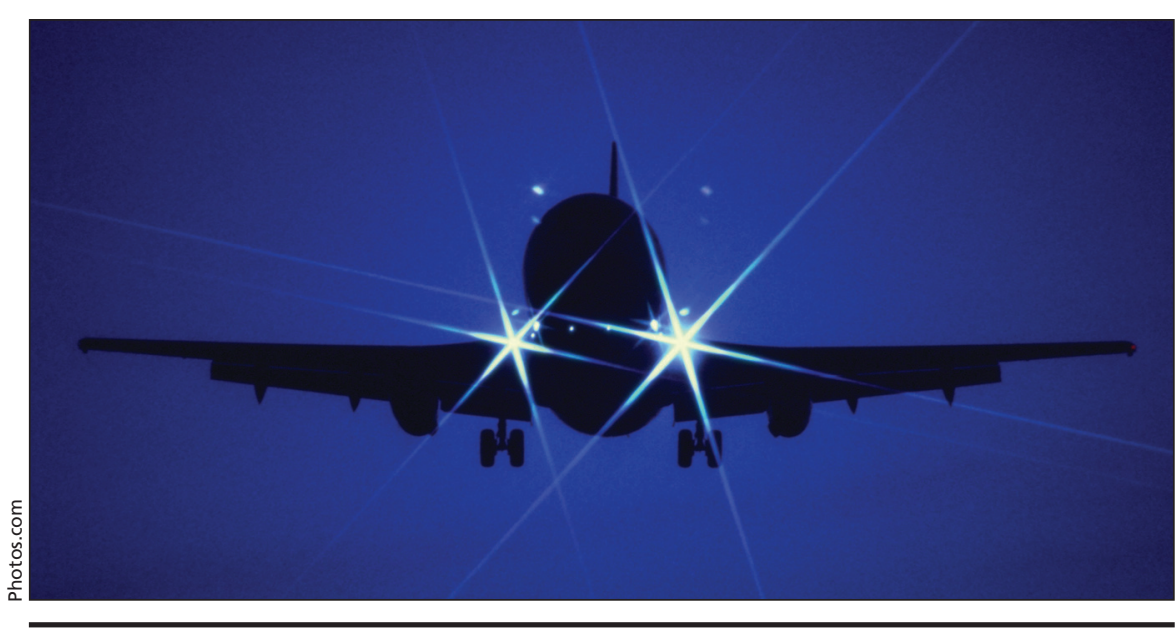

After a month at multinational medical unit in Khandahar, Afghanistan, Dr. Jorge Zamora reflects on his experiences while flying home to Kingston, Ontario.

been relatively lucky. Before he lost consciousness I spoke softly and told him: "They're going to be alright. ... Don't worry. ... Take some deep breaths. ... Close your eyes. ... You're all in good hands here."

My thoughts shifted to a week later, when 4 of our surgeons were in the operating room working to stop bleeding, debride the wounds and apply external fixators to the shattered limbs of a wounded soldier. The anesthesia team was administering blood products as quickly as we possibly could.

We were still working on the soldier when we received word - 3 Canadians had been killed in a separate incident.

Their ramp ceremony was held on the airfield the next day.

As I recall, it was almost dusk. Three armoured vehicles, their rear doors open, slowly rumbled to their positions on the tarmac at the end of 2 columns formed by several thousand soldiers. Inside each of their dimly lit interiors was a casket draped with a Canadian flag.

The Task Force was brought to attention and then to a salute as the fallen and their bearers slowly made their way towards the dark grey silhouette of a Hercules.

For a few moments the airfield, usu- ally a hectic and noisy place busy with helicopter, jet and transport traffic, was uncharacteristically silent. And peaceful. The sun had set and a cold breeze was blowing in from the nearby mountains. A crescent moon and several stars were now visible in the clear night sky. The only sound was that of the piper playing his lament.

I leave Khandahar airfield with mixed feelings. Although I am looking forward to returning home, I am sad to be bidding farewell to some of the best people and finest teams that I have ever worked with.

My thoughts drift back to the present as I notice the increasing noise and vibration from our aircraft's engines. We are already in the air, homeward bound. — Dr. J.E. Zamora, Khandahar, Afghanistan

DOI:10.1503/cmaj.090627

CMAJ invites contributions to "Dispatches from the medical front," in which physicians and other health care providers offer eyewitness glimpses of medical frontiers, whether defined by location or intervention. Submissions, which must run a maximum 700 words, should be forwarded to: wayne.kondro@cmaj.ca. 